\title{
Uncertain Range Non-Negative Integer Data Type
}

National Cancer Institute

\section{Source}

National Cancer Institute. Uncertain Range Non-Negative Integer Data Type. NCI

Thesaurus. Code C95685.

A data type comprised of an uncertain range of integers that are non-negative. 